\title{
Application of real-time (RT-PCR) for detection of Salmonella Typhi among febrile patients in Khartoum
} \section{state}

\begin{abstract}
Background: Typhoid fever, caused by Salmonella enteric sero-var Typhi remains a public health threat in many countries particularly those with poor sanitary conditions. Ambulatory health care facilities in endemic settings frequently lack laboratory-based diagnostics, resulting in the majority of diagnosis being made clinically and antimicrobials given empirically so we need more developed and specific methods. To detect the causative agents. The objective of this study was to apply Real-time (RT-PCR) for detection of salmonella Typhi among febrile patients at Khartoum state-Sudan.
\end{abstract}

Methods: Blood samples were taken from 100 suspected typhoid cases, they were subjected to conventional blood culture; widal agglutination test and real-time PCR. Blood culture was performed using standard protocol and real time PCR targeting prg K gene.

Result: Out of 100 suspected typhoid cases blood culture were positive in 24 cases. The Real-time assay identified 20 cases $(83 \%)$ as positives among the 24 culture Positive cases. However, the assay additionally detected $20(26 \%)$ of cases as Salmonella infection among culture negative patients. Widal test was positive in $16(66.6 \%)$. Cases among culture positive cases. However, the test additionally was positive in $44(57.8 \%)$ cases among culture negative cases.

Conclusions: Our study conclude that PCR Real-time is a rapid, sensitive, and specific test for the diagnosis of typhoid fever especially during antibiotic treatment and/or cultured one in late stages of disease.

Keywords: real-time (RT-PCR), Salmonella Typhi, febrile patients
Volume 8 Issue 5 - 2020

\author{
Alsayid A Aldusogi,' Khalid A Enan² \\ 'Department of Medical Microbiology, Faculty of Medical \\ Laboratory Sciences, El Neelain University, Sudan \\ ${ }^{2}$ Department of Virology, Central Laboratory-The Ministry of \\ Higher Education and Scientific Research, Sudan
}

Correspondence: Khalid A Enan, Department of Virology, Department of Virology Central Laboratory, Ministry of Higher Education and Scientific Research, Khartoum, Sudan, Email khalid.ean@gmail.com

Received: September 14, 2020 | Published: October 28, 2020

\section{Background}

Typhoid fever, which is caused by the Salmonella enterica sero-var Typhi, remains a public health threat in many countries particularly those with poor hygiene and sanitary conditions. Approximately 21 million new cases appear and 216,000 deaths are caused by typhoid fever each year worldwide. ${ }^{1}$ Patients with typhoid fever have a non-specific presentation that is similar with other febrile illnesses such as S. para typhi, Liptospirosis, and Streptococcus pneumoniae infections. $^{2,3}$ Highlighting the importance of accurate etiological diagnosis of this disease. Bacterial culture is an ordinarily used for diagnosis of typhoid fever. However it is considered as the gold standard of diagnosis, but it is time-consuming (at least 3-5 days) and has low sensitivity (30-60\%)., A rapid, simple and cheap technique for specific diagnosis of S. Typhi infections thus needed especially in the regions with high incidence of salmonellosis.

Several immunological methods including Widal test, Typhi-Dot, Tubex ${ }^{6}$ lateral flow ${ }^{7}$ and $\mathrm{SPR}^{8}$ based on the types of $\mathrm{O}$ and $\mathrm{H}$ surface antigens have already been developed for detection of S. Typhi. Despite their simplicity and rapidity, the accuracy of these assays is relatively low and is susceptible to be influenced by the process of the disease. The judgment of the immunological reaction depends on the antibody production and its titer, which usually starts at least one week after S. Typhi infection, preventing early diagnosis by this approach. In addition to conflicting results in terms of specificity and sensitivity of these serological tests were presented indifferent typhoid endemic areas. ${ }^{6,9,10}$ Such as the SPR technique for diagnosis of S. Typhi was judged as to need further validation under filed conditions. The nucleic acid amplification tests with the advantages of being rapid, specific and sensitive, have been applied to diagnosing S. Typhi by targeting certain genes. ${ }^{11,12}$ However, these techniques are yet to be fully exploited due to the major limitations of the requirements for a thermal cycler; relatively expensive reagents and skilled personnel.

\section{Materials and methods}

Study design: Descriptive cross sectional study.

Study area: This study was carried out at the laboratories of faculty of Medical laboratory sciences-Omdurman Ahlia University (OAU).

Study period: From May 2018 to October 2019.

Sample size: One hundred patients were enrolled in this study.

Study population: Patients with suspected enteric fever was included in the study.

Selection criteria: The criteria of selection of patients included clinical presentation compatible with enteric fever such as fever associated symptoms, signs including abdominal pain, nausea, vomiting, constipation, or diarrhea and complications, Only those cases suspected of having enteric fever were included in the study.

Data collection: Data were collected through well designed questionnaire, contained all the required details.

\section{Methods}

Peripheral blood samples collected from each patient including $5 \mathrm{ml}$ in $50 \mathrm{ml}$ of BHIB (i.e., 1:10 dilution) for blood culture; $2 \mathrm{ml}$ 
blood in EDTA vial for PCR and $3 \mathrm{ml}$ blood in plain tubes for Widal test. Commercially prepared colored antigen, used S. Typhi O and $\mathrm{H}$ antigens, patients' sera tested for Agglutinins against each of the different Salmonella suspensions and the Widal agglutination test against Salmonella Typhi O antigen titer of 1:160 in the single Sera or more considered positive. Under aseptic precautions, $5 \mathrm{ml}$ of blood collected and inoculated into Brain Heart Infusion (BHI) broth. Bottles checked daily for any evidence of growth. If no visible growth occurred, blind subculture performed. Any colony obtained on subculture identified by biochemical test and confirmed by specific antisera. Total DNA extracted by using SDS and proteinase $\mathrm{K} .(0.25 \mathrm{ml})$ of each serum thawed and centrifuged for 10 minutes at $12.000 \mathrm{~g}$ and then the pellets re-suspended in $0.2 \mathrm{ml}$ of digestion buffer [50mM Tris-HC1(pH 8.5), 1mM EDTA, 0.5\%SDS, 200i g/ $\mathrm{ml}$ proteinase $\mathrm{K}]$ and incubated for 3 hours at $55^{\circ} \mathrm{C}$ with agitation (Thermo-mixer, Eppendorf). After heat inactivation of the proteinase $\mathrm{K}$ for 10 minutes at $95^{\circ} \mathrm{C}$, tubes cooled to $4^{\circ} \mathrm{C}$ and centrifuged for 10 minutes at $12,000 \mathrm{~g}$. Ten micro liters of the supernatant used directly for PCR amplification.

Real-time PCR, master-mix prepared as per manufacturer instruction. Master- Mix for a single reaction prepared by mixing $0.5 \mu \mathrm{l}$ each of forward primer, reverse primer. $10 \mu \mathrm{l}$ of Sybr-Green probe master and $6 \mu 1$ of distilled water added to it, so that for a single reaction, $17 \mu$ l of master-mix solution prepared. 96 wells special plate used in light cycler 480 to run Real-Time PCR reaction. In each well $7 \mu l$ master-mix was added with $3 \mu 1$ of specimen DNA. Pure culture DNA extract of Salmonella typhi used as positive and Escherichia coli, Acinetobacter baumanni, and Streptococcus pneumoniae used as negative controls.

\section{Results}

None of the control group proved positive for S. typhi by any of the 3 diagnostic methods used. Blood culture grew Salmonella typhi in 24 patients. Rest of the cultures sterile after 7 days of incubation. No other bacterial species isolated in these patients. No patient with history of prior antibiotic intake showed positive blood culture, a total of $40 \%$ of the patients confirmed to have Salmonella infection using real-time PCR. The Real-time assay identified 20 cases $(83 \%)$ as positive among the 24 culture positive cases. However, the assay additionally detected $20(26.31 \%)$ of cases as Salmonella infections among culture negative patients. Widal test was positive in $16(66.6 \%)$ cases among culture positive cases. However, the test additionally. The Kappa value was positive in $44(57.8 \%)$ cases among culture negative cases. Determined to find agreement between RealTime PCR, conventional blood culture, the sensitivity and specificity of Real-Time PCR assay determined to be $83.33 \%$ and $73.68 \%$ using blood culture as gold standard. No images accompanied because we use real time PCR not conventional PCR.

\section{Discussion}

Use of blood culture as a screening test in patients with fever yield lower positivity rate for S. Typhi high variation in isolation rates have been attributed to the amount of blood subjected to culture, the level of bacteremia, the type of culture medium used, stage of illness and prior exposure to antibiotics although only $21 \%$ of patients gave history of prior antibiotic intake at the time of blood collection. The real time PCR assay identified 40 cases of Salmonella infection in 100 clinically suspected cases. We found potential advantage of real time PCR in that it may be performed on smaller volumes of blood than required for culture. Another advantage of the PCR assay is its ability in diagnosing patients with history of prior antibiotic intake this is probably the reason for detection of additional four cases by PCR assay among patients with history of antibiotic intake in our study, PCR using prg K gene was found suitable in our setting. PCR detection of Salmonella typhi took less than 24 hours, compared with three to five days for blood culture. The second most commonly used and preferred diagnostic tool for typhoid fever is the widal agglutination test, which had limitations such as low sensitivity and limited benefits when one serum sample was obtained.

\section{Conclusions}

Therefore, PCR being a rapid, sensitive, and specific test for the diagnosis of typhoid fever, especially where blood culture was negative because of prior antibiotic treatment and culture done in late stages of disease, should be introduced especially in tertiary hospitals to avoid diagnosis delay and to enable the clinician to use appropriate treatment.

\section{Acknowledgments}

None.

\section{Conflicts of interest}

Authors declare that there is no conflict of interest.

\section{References}

1. Crump JA, Mintz ED. Global trends in typhoid and paratyphoid Fever. Clin Infect Dis. 2010;50(2):241-246.

2. Petit PL, Wamola IA. Typhoid fever: a review of its impact and diagnostic problems. East African Medical Journal. 1994;71(3):183-188.

3. Murdoch DR, Woods CW, Zimmerman MD, et al. The etiology of febrile illness in adults presenting to Patan hospital in Kathmandu, Nepal. Am J Trop Med Hyg. 2004;70(6):670-675.

4. WHO. Background document: The diagnosis, treatment and prevention of typhoid fever. Communicable Disease Surveillance and Response Vaccines and Biologicals; 2003.

5. Bhuta ZA. Current concepts in the diagnosis and treatment of typhoid fever. BMJ. 2006;333(7558):78-82.

6. Naheed A, Ram PK, Brooks WA, et al. Clinical value of Tubex and Typhid rapid diagnostic tests for typhoid fever in an urban community clinic in Bangladesh. Diagn Microbiol Infect Dis. 2008;61(4):381-386.

7. Nakhla I, El Mohammady H, Mansour A, et al. Validation of the DriDot Latex agglutination and IgM lateral flow assays for the diagnosis of typhoid fever in an Egyptian population. Diagn Microbiol Infect Dis. 2011;70(4):435-441.

8. Singh A, Verma HN, Arora K. Surface Plasmon Resonance Based Label-Free Detection of Salmonella using DNA Self Assembly. Applied Biochemistry and Biotechnology. 2015;175:1330-1343.

9. Olsen SJ, Pruckler J, Bibb W, et al. Evaluation of rapid diagnostic tests for typhoid fever. J Clin Microbiol. 2004;42(5):1885-1889.

10. Dong B, Galindo CM, Shin E, et al. Optimizing typhoid fever case definitions by combining serological tests in a large population study in Hechi City, China. Epidemiol Infect. 2007;135(6):1014-1020.

11. Ali A, Haque A, Sarwar Y, et al. Multiplex PCR for differential diagnosis of emerging typhoid pathogens directly from blood samples. Epidemiol Infect. 2009;137(1):102-107.

12. Francois P, Tangomo M, Hibbs J, et al. Robustness of a loop-mediated isothermal amplification reaction for diagnostic applications. FEMS Immunol Med Microbiol. 2011;62(1):41-48. 